Supporting Information

\title{
Flexible Multifunctional Photonic Crystal Fibers with Shape Memory Capability for Optical Waveguides and Electrical Sensors
}

Jie Cheng, Lele Zhang, Kai Zhao, Yunpeng Wang, Xianfei Cao, Shufen Zhang, Wenbin Niu*

State Key Laboratory of Fine Chemicals, Dalian University of Technology,

West Campus, 2 Linggong Rd., Dalian 116024, China.

E-mail: niuwb@dlut.edu.cn

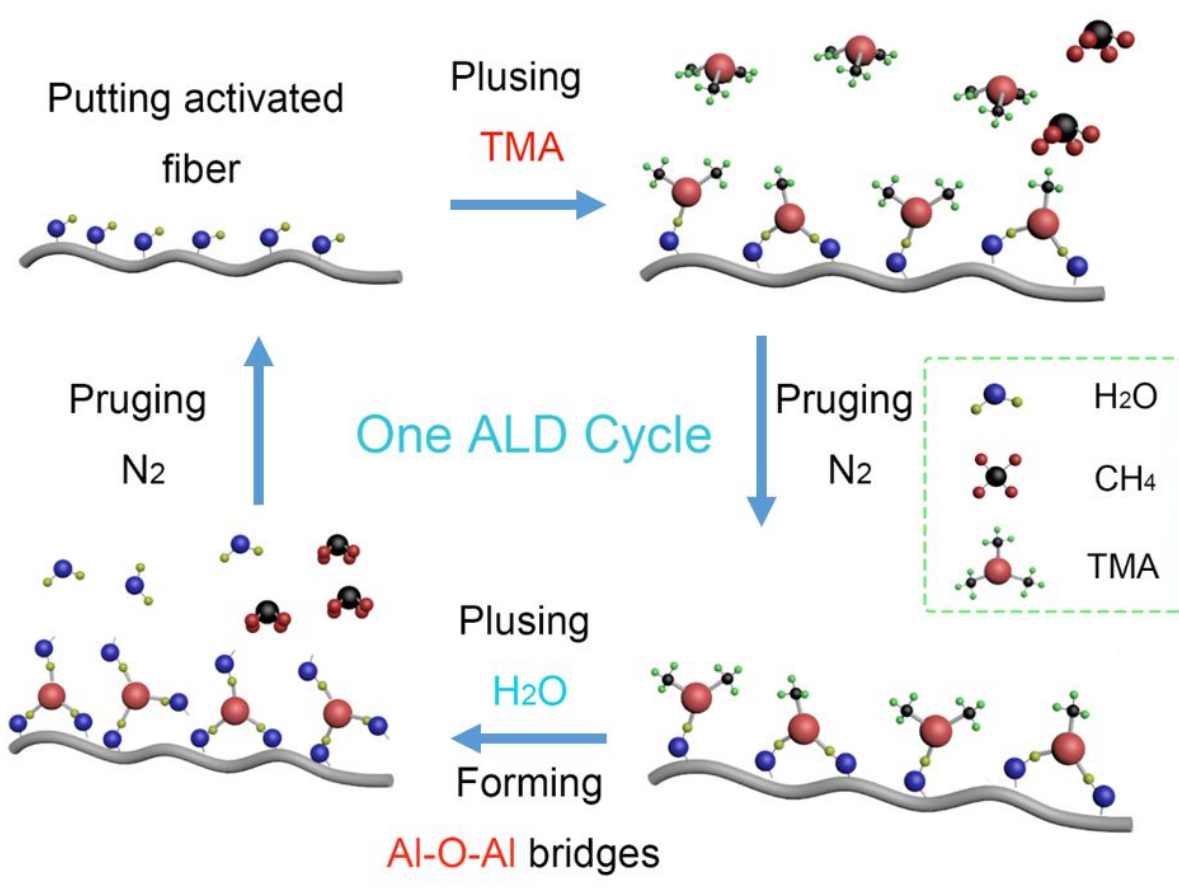

Figure S1. Schematic illustration of $\mathrm{ALD}$ mechanism using $\mathrm{Al}_{2} \mathrm{O}_{3}$ as a sample, where 
TMA refers $\mathrm{Al}\left(\mathrm{CH}_{3}\right)_{3}$.

$\mathrm{Al}_{2} \mathrm{O}_{3}$ multilayer deposition can be achieved by repeating the above steps in the deposition process. The main process can be summarized as the following equation:

$$
\begin{gathered}
(1)-\mathrm{AlOH}+\mathrm{Al}\left(\mathrm{CH}_{3}\right)_{3} \rightarrow-\mathrm{Al}-\mathrm{O}-\mathrm{Al}\left(\mathrm{CH}_{3}\right)_{2}+\mathrm{CH}_{4} \\
(2)-\mathrm{Al}-\mathrm{CH}_{3}+\mathrm{H}_{2} \mathrm{O} \rightarrow-\mathrm{AlOH}+\mathrm{CH}_{4} \\
2 \mathrm{Al}\left(\mathrm{CH}_{3}\right)_{3}+3 \mathrm{H}_{2} \mathrm{O} \rightarrow \mathrm{Al}_{2} \mathrm{O}_{3}+3 \mathrm{CH}_{4}
\end{gathered}
$$

Table S1. Comparison of the theoretical band gap wavelengths and the measured reflection peaks of structural colored fibers.

\begin{tabular}{ccccc}
\hline & \multicolumn{2}{c}{ Film } & Theoretical bandgap & Reflection peak \\
Sample & \multicolumn{2}{c}{ thickness(nm) } & wavelength(nm) & wavelength(nm) \\
& $\mathrm{Al}_{2} \mathrm{O}_{3}$ & $\mathrm{ZnO}$ & & \\
\hline PET-3(400+300) & 60 & 62 & 439.8 & 444.76 \\
PET-3(400+400) & 60 & 78 & 502.2 & 478.07 \\
PET-3(400+500) & 60 & 106 & 611.4 & 729.65 \\
PET-3(400+600) & 60 & 132 & 712.8 & \\
\hline
\end{tabular}



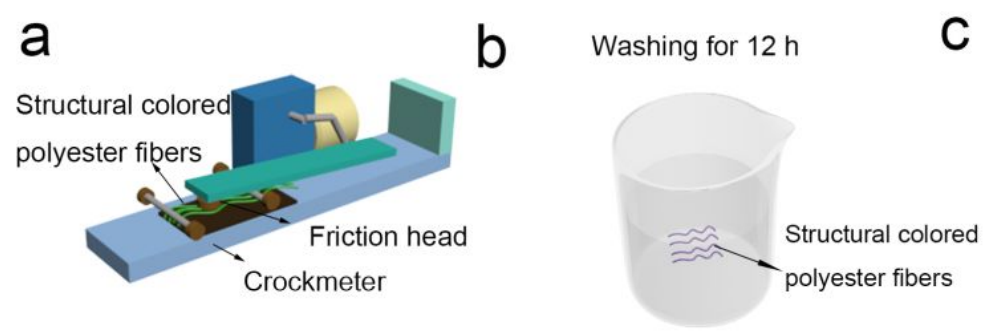

Solar radiation test for 7 days
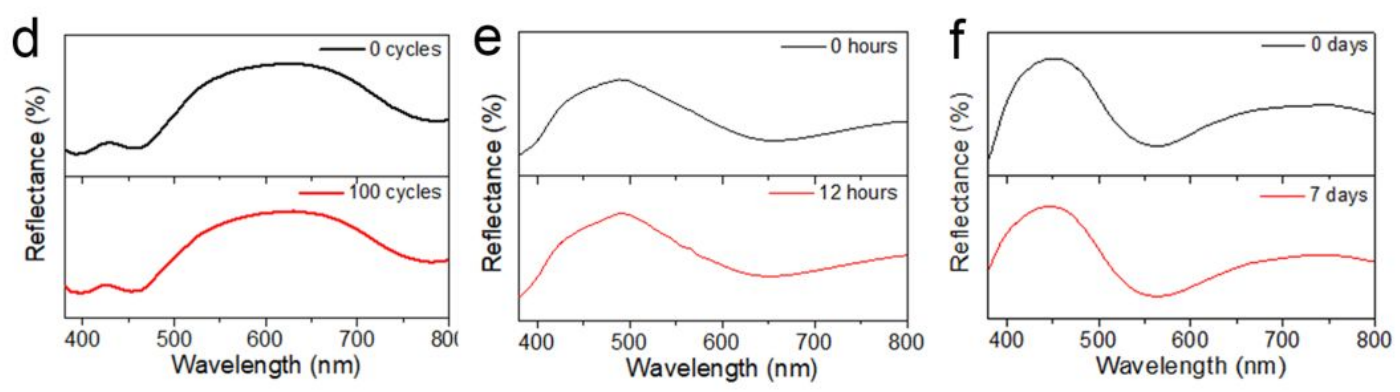

Figure S2. (a) Schematic of the mechanical rubbing test performed using a crockmeter with a load pressure of $50 \mathrm{kPa}$ for 100 cycles, and (d) reflection spectra of PET-3(400+500) before and after rubbing test. (b) Schematic of the laundering test at $1200 \mathrm{rpm}$ for $12 \mathrm{~h}$, and (e) reflection spectra of PET-3(400+400) before and after laundry test. (c) Schematic of the accelerated light-aging test and (f) reflection spectra of PET-3(400+300) before and after accelerated light-aging test using a Sunlight Climate Tester YG(B)911-V. Temperature: $40{ }^{\circ} \mathrm{C}$, humidity: $50 \%$ and irradiance 1.1 $\mathrm{W} / \mathrm{m}^{2}$ at $420 \mathrm{~nm}$, time: 7 continuous days. 


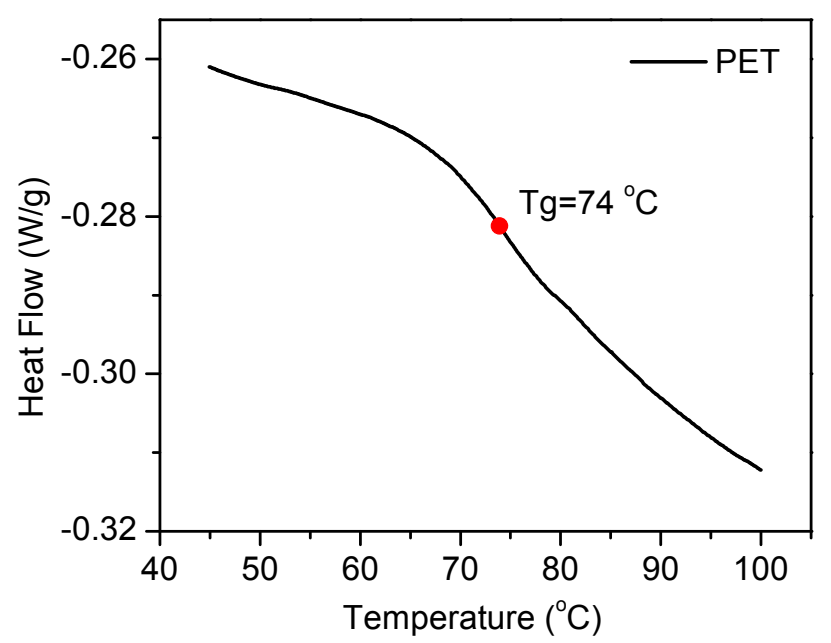

Figure S3. DSC thermogram of the polyester fibers.

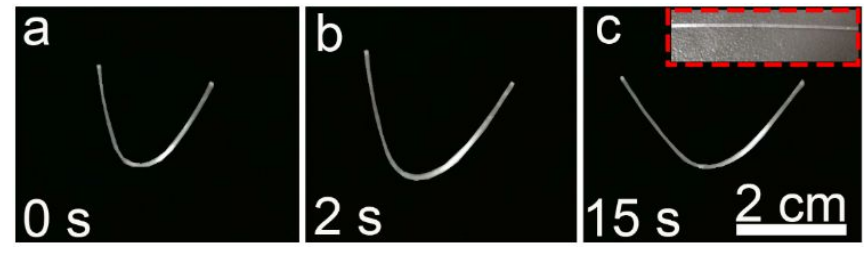

Figure S4. Digital photos of transparent polyester fiber changing with time at $130^{\circ} \mathrm{C}$.

(a) $0 \mathrm{~s}$, (b) $2 \mathrm{~s}$, (c) $15 \mathrm{~s}$, and the inset shows the straight shape of the polyester fiber.

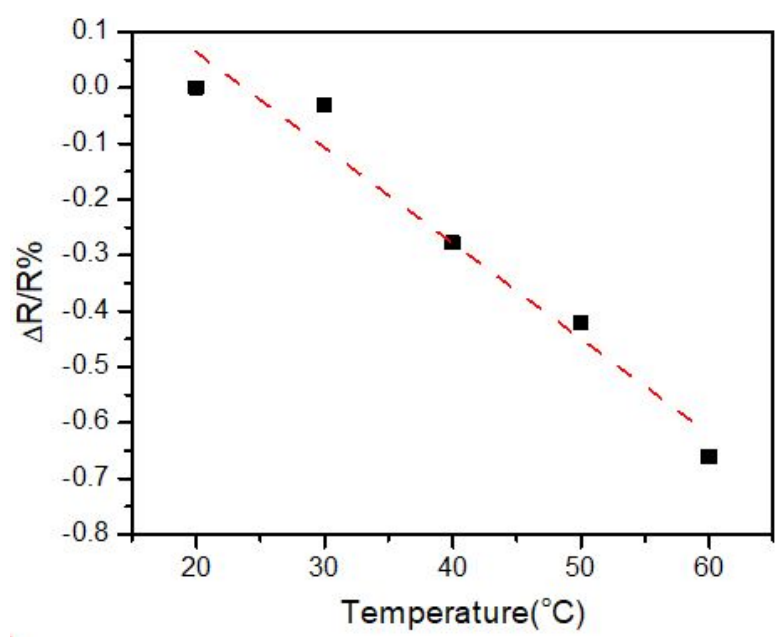

Figure S5. Normalized resistance changes of the temperature sensor. 


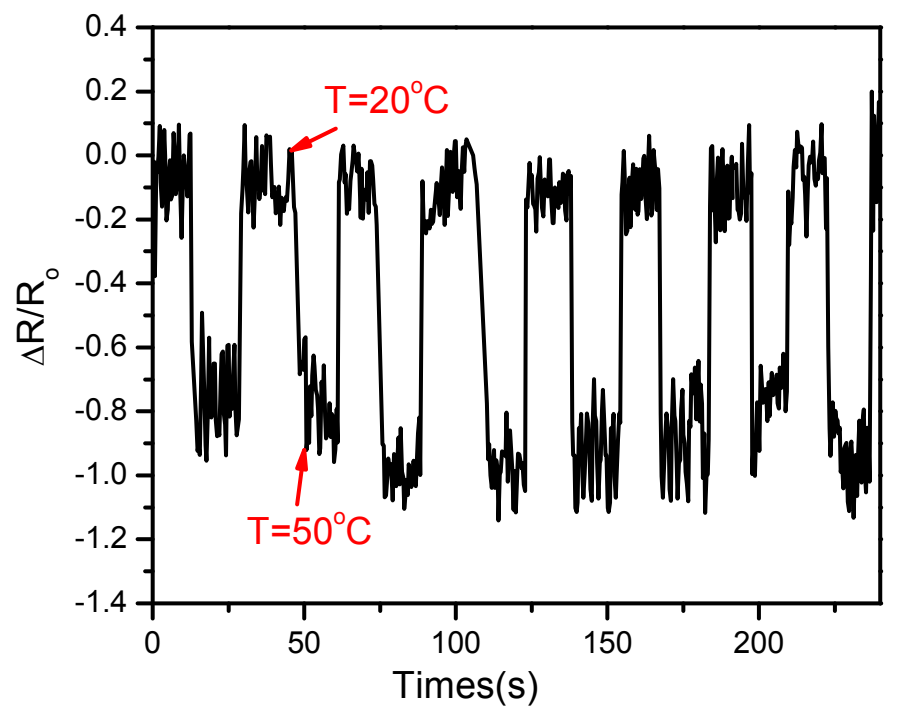

Figure S6. Cycle test of temperature sensor between $20^{\circ} \mathrm{C}$ and $50{ }^{\circ} \mathrm{C}$.
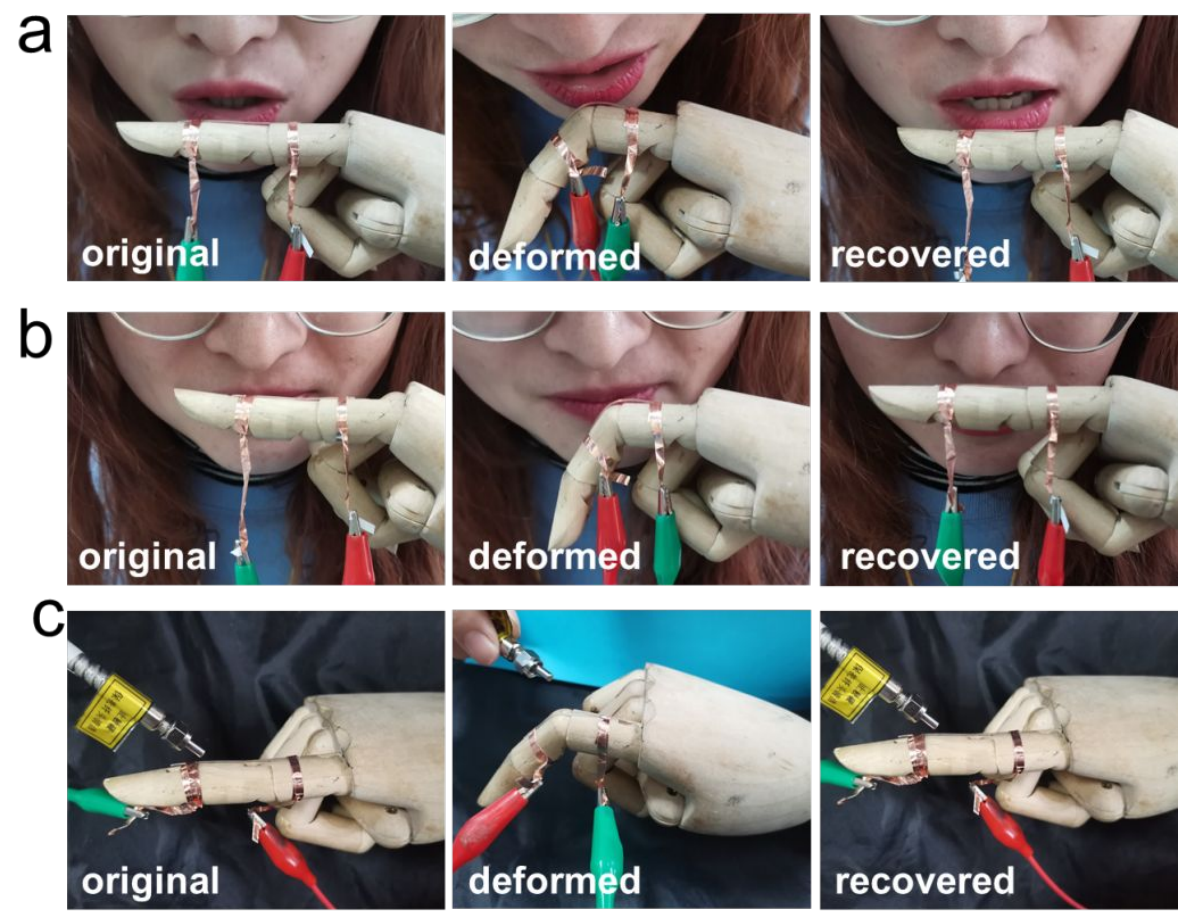

Figure S7. The test photos of (a) mouth respiration, (b) nose breathing and (c) infrared light tests of the sensor in original, deformed and recovered state. 